\title{
Trauma e reconhecimento na clínica psicanalítica
}

\section{Trauma and recognition in psychoanalytic clinic}

Stephanie Brum*1

O presente artigo objetiva traçar considerações acerca do reconhecimento na clínica psicanalítica. Para tal, traçaremos um contraponto deste com o trauma. Nesse contexto, nos deparamos com o reconhecimento que, por sua vez, se apresenta não apenas como a forma de cuidado promovido por uma adaptação ambiental suficientemente boa, como também enquanto um posicionamento ético assumido na própria clínica. Por outro lado, o traumático surge como uma falha do ambiente em reconhecer as necessidades do indivíduo e mediar sua vulnerabilidade na relação com o meio.

Palavras chave: Trauma, reconhecimento, testemunho, vulnerabilidade, presença

*1 Pontifícia Universidade Católica do Rio de Janeiro - PUC-Rio (Rio de Janeiro, RJ, Brasil). 


\section{Introdução}

Muito tem se estudado na psicanálise contemporânea acerca de modalidades de adoecimento, dinâmicas psíquicas e formas de sofrimento que não se centram na problemática edípica - embora isso não a exclua de cena. Nesse contexto, a teoria ferencziana do trauma nos apresenta um novo quadro, direcionando-nos a uma dinâmica distinta que traz à tona a importância tanto de um modelo de funcionamento intrapsíquico quanto do campo relacional.

De acordo com as proposições de Ferenczi, o trauma faz parte do desenvolvimento psíquico. Da mesma forma, o mecanismo da cisão se apresenta como fundamental para a constituição subjetiva (Ferenczi, 1924/2011b). Tal consideração implica reconhecermos no traumático não apenas uma faceta patológica e desestruturante como também um movimento importante para a própria complexificação do aparelho psíquico. Seguindo esta linha, podemos pensar o trauma como o motor que impulsiona o sujeito inevitavelmente à mudança, desencadeando movimentos que se apresentam como saídas possíveis a fim de afirmar a própria vida. Ou seja, a incidência do traumático desencadeia adaptações em prol da proteção e sobrevivência do indivíduo. Assim, os diversos modos de adaptação diante do trauma carregam tanto um novo meio de organização da dinâmica intrasubjetiva como também formas de resistência da própria vida (Brum, 2018). Este último ponto se expressa enquanto fundamental ao afirmarmos os caminhos e descaminhos possíveis em resposta ao traumático como uma forma de posicionamento ativo em direção à própria manutenção da vida (Brum, Câmara \& Sanzana, 2020). Dito isso, o que desencadeia a faceta desestruturante do evento traumático se este em si trabalha em prol de desenvolvimento do próprio psiquismo?

Ferenczi formula em sua teoria do trauma que o caráter desestruturante do trauma é decorrente da negação da experiência do sujeito por uma figura de confiança (Pinheiro, 1995; Kupermann, 2019; 


\section{ARTIGOS}

Lejarraga, 2008). Deste modo, o desmentido acarreta não apenas a negação do evento vivenciado, como também põe em xeque a capacidade do indivíduo de confiar em suas próprias vivências. Nesse ponto chama nossa atenção uma possível falha na função de testemunho demandada a este terceiro que, segundo Kupermann (2019), ao ver-se diante do horror, da angústia e da dor do trauma se desorienta e o nega não apenas para o sujeito traumatizado, mas também para si mesmo. O autor apresenta, então, uma faceta do traumático que é insuportável tanto para o sujeito traumatizado quanto para sua testemunha eleita, que nega o evento não como um ato consciente ou mesmo uma atitude perversa diante do ocorrido, mas como forma de defesa ante o lugar de testemunha do ponto catastrófico que pode chegar à crueldade ao colocar o outro na posição de objeto.

Desta forma, a dialética do desmentido nos coloca diante da importância do testemunho, capaz de atuar em prol da função de reconhecimento. Tal ponto nos leva a traçar nossas considerações a partir de um entrelaçamento entre trauma e reconhecimento, entendendo o reconhecimento como uma função essencial ao desenvolvimento e constituição psíquica do indivíduo e assim também contraposta ao traumático na vertente oposta. A oposição entre trauma e reconhecimento nos faz afirmar o segundo como negativo do primeiro, o que concede grande importância a seu estudo na clínica contemporânea. Nesta linha, deparamo-nos com as considerações de Gondar (2012) que, ao apontar o desmentido do trauma como uma recusa do reconhecimento, nos direciona a toda a importância desta dinâmica na constituição subjetiva. Esta relevância se inscreve na medida em que acreditamos que a utilização do reconhecimento enquanto posicionamento ético e manejo clínico pode se apresentar como ferramenta potente no atendimento das variadas facetas e formas de vida em fragmentos (Brum, 2018) que vem se tornando frequentes em nossos consultórios.

Direcionando-nos ao reconhecimento, este é apresentado por Gondar (2012) como uma "[...] necessidade vital que possui todo indivíduo de ser visto, ouvido, aprovado e respeitado pelas pessoas que o cercam, [...]" (p. 199). Ou seja, para ser para si é necessário ser reconhecido pelo outro (Honneth, 1992/2003), ser reconhecido em seu lugar de sujeito capaz de desejar e ter experiências e expressões únicas. Honneth (1992/2003) traz uma dupla faceta da dinâmica reconhecer $x$ ser reconhecido ao apontar esta como ao mesmo tempo concomitante e natural na medida em que o ser reconhecido surge como possibilidade de formação do próprio ser que então se tornará também capaz de reconhecer. Tal consideração nos coloca diante da problemática da formação 
do ser que paira no cerne das relações de reconhecimento. Da mesma forma torna possível pensar suas falhas como remetidas à instância traumática da angústia do não ser, em diferentes gradações.

Como vimos, a falha do reconhecimento pode desencadear um movimento de ruptura no próprio sentimento de si, promovendo angústias, sensação de irrealidade e mesmo não veracidade das experiências vividas. Contudo, ainda nos questionamos de que forma essa função atua em prol do desenvolvimento subjetivo e da descoberta e criação do si mesmo.-

\section{O não lugar do traumático}

Ao adentrarmos no terreno das relações objetais deparamo-nos com uma dinâmica relacional paradoxalmente unitária e dual com o outro. Este, por sua vez, ao atribuir reconhecibilidade também reconhece o que de próprio se expressa no cerne de sua relação tão particular com aquele sujeito em processo de ser. Para Ferenczi, o mundo externo e as relações primordiais do sujeito ganham grande relevo e, neste contexto, a figura do outro também se destaca. "Em suma, em lugar dos fatores endógenos, seriam sobretudo os fatores externos ao sujeito os grandes perturbadores do aparelho psíquico" (Pinheiro, 1995, p. 35). Percebemos a potência de tal afirmação quando, em 1909, Ferenczi afirma o lugar dos movimentos de introjeção e projeção no desenvolvimento subjetivo, enriquecimento e sobrevivência do mundo interno. Posteriormente, em meio à formulação de sua teoria do trauma, o autor apresenta o outro como uma figura de cuidado, amor e confiança da qual a criança traumatizada não pode abrir mão. Assim, diante da impossibilidade de defender-se aloplasticamente da situação traumática uma defesa autoplástica ocorre, desencadeando uma cisão no próprio eu a fim de promover não apenas a mudança necessária, mas a mudança possível diante do ocorrido. Neste quadro temos ainda o outro como figura a quem a criança atribui o lugar de testemunha na busca pela afirmação de seu vivido. Esses diferentes lugares que o outro assume ao longo da obra ferencziana nos fazem compreender a importância que o olhar deste adquire para o psiquismo, sendo capaz de exercer um veredicto sobre o próprio indivíduo ao atestar sua vivência ou mesmo conceder-lhe um lugar.

É justamente a capacidade de predizer uma verdade tão mortal sobre o indivíduo - capaz de pôr em xeque toda a confiança que este tem sobre si mesmo - que nos chama a atenção na teoria do trauma ferencziano. 


\section{ARTIGOS}

Deparamos-nos aqui não apenas com uma negação do ocorrido, mas com uma dinâmica que atravessa o sujeito com um olhar incapaz de capturar sua dor. Um olhar que parece não dar conta de todo o horror que a experiência traumática traz à tona, negando-o a fim de também se proteger de todo esse horror (Pinheiro, 1995; Kupermann, 2019). A força devastadora do desmentido se encontra não na negativa lançada sobre a experiência, mas sobre o próprio sujeito. Tal consideração nos leva a depreender o não lugar no qual a voz de uma testemunha que desmente o próprio indivíduo pode lançá-lo, destroçando a cadeia de sentidos que se forma a partir da afirmação de suas experiências vividas e aquisição de significados e construções tanto fantasmáticas quanto afetiva sobre as mesmas (Brum, 2019).

Outro ponto levantado por Gondar (2012) é o fato de o desmentido - e aqui acrescentamos que a própria confusão de línguas também assume esse lugar - desconsiderar a vulnerabilidade do sujeito mesmo antes do evento traumático. Ou seja, para que a violência se dê o reconhecimento do próprio sujeito e de sua vulnerabilidade tem que ser negados a priori. Em 1929, Ferenczi se dedica ao estudo dos indivíduos não desejados. Nesse trabalho, o autor afirma a possibilidade de uma sensação de que a vida não valeria a pena ser vivida em sujeitos cujo ambiente não foi capaz de promover a sustentação adequada na mais tenra infância. É a partir da importância lançada sobre o acolhimento, o amor e o desejo, necessários para que o sujeito constitua um sentimento de valia sobre a própria vida e direcionamento à mesma, que Ferenczi introduz nesse trabalho a temática ambiental. Para ele, o meio deve estar pronto para assumir a função de cuidado que lhe é cabida. Consideramos que o não reconhecimento dessa necessidade infantil já se constitui por si só enquanto uma falha capaz de transformar o processo de desenvolvimento e a sequência de traumas a ele inerente em algo desestruturante para o indivíduo.

A criança deve ser levada, por um prodigioso dispêndio de amor, de ternura e de cuidados, a perdoar aos pais por terem-na posto no mundo sem lhe perguntar qual era a sua intenção, pois, caso contrário, as pulsões de destruição logo entram em ação. E, no fundo, não há motivos de espanto, uma vez que o bebê, ao contrário do adulto, ainda se encontra muito mais perto do não ser individual. (Ferenczi, 1929/2011c, p. 58)

Nesse contexto, afirmamos o desestruturante do traumático como o atravessamento do sujeito pelo olhar do outro que, ao não fixar-se em sua figura, é incapaz de testemunhar seu viver. Aqui, somos remetidos à imagem da mãe morta (Green, 1988) que é incapaz de depositar o olhar em 
seu bebê, acolher e responder à sua espontaneidade, dando contorno à sua existência e afirmando seu lugar enquanto indivíduo. Green (1988) aponta que "A transformação na vida psíquica, no momento do luto súbito da mãe que desinveste brutalmente seu filho, é vivida por ele como uma catástrofe" (p. 248), e ainda que o "trauma narcisista que esta mudança representa [...] constitui uma desilusão antecipada e que provoca, além da perda de amor, uma perda de sentido [...]" (p. 248). Tanto no caso do desmentido traumático quanto da presença ausente da mãe morta, a consequência psíquica para o sujeito é a identificação completa com o objeto. Não sabendo como lidar com o outro, e desprovido de sentido diante de tentativas fracassadas de obter uma resposta a si, o mimetismo se torna a única saída possível. Além disso, o indivíduo se depara não apenas com a negativa de si mesmo, mas com a consequência de uma introjeção que o torna o próprio outro do qual não é capaz de abrir mão na tentativa de revestir as cicatrizes traumáticas. Diante do trauma desestruturante, as falhas sofridas na função de reconhecimento - que aqui englobam o amparo, adaptabilidade do meio, expressão de si e identificação da vulnerabilidade do sujeito - lançam o indivíduo em um terreno no qual sua própria existência e expressão espontânea são negadas.

A teoria ferencziana do trauma e a potência desestruturante que o desmentido é capaz de assumir nos direciona para a ideia de reificação trabalhada por Honneth (2006/2018). O autor propõe uma atualização da temática da reificação considerando que esta não estaria referida apenas a uma lógica econômica capitalista, mas às diversas formas que as relações podem tomar. Tal consideração não desconsidera a influência de uma lógica de mercado, mas amplia suas implicações para uma vertente intersubjetiva que se mostra extremamente frutífera na discussão de nossa temática.

Nesse contexto, a reificação seria uma forma de anulação da individualidade, humanidade e mesmo de características pessoais em prol de uma relação que passa a se estabelecer a partir de uma lógica de "coisificação" do sujeito. O movimento proposto seria proveniente de um não reconhecimento da individualidade dos sujeitos, utilizando-se de suas vidas e seus corpos de maneira objetificada, atribuindo-lhes valorações externas. A aproximação proposta entre reificação e trauma se inscreve na medida em que, ao desconsiderar a singularidade do indivíduo, é lançado sobre ele um olhar que ao mesmo tempo que lhe atravessa lhe impõe valorações, sentidos, adjetivos e desejos externos, os quais passam a ser vivenciados como próprios. $\mathrm{O}$ não reconhecimento da espontaneidade do indivíduo poda a expressão de sua singularidade, lançando o sujeito em uma vivência dotada de passividade 


\section{ARTIGOS}

a partir da qual se torna observador em vez de agente criador de uma vida significativa.

Nesse sentido, o trauma se daria em suas múltiplas vertentes em decorrência de um movimento reificante de um meio que em sua inadaptação se torna também inábil em reconhecer e responder as expressões do indivíduo seja em termos de sua espontaneidade ou experiências vividas. É justamente neste movimento que não atenta para as necessidades e vulnerabilidades de um indivíduo que se encontra em constante processo de constituição de si, que a negativa, o atravessamento e a desconsideração se apresentam como traumáticos.

\section{O estabelecimento de um lugar a partir do reconhecimento}

Ao nos direcionarmos para o que consideramos o outro polo desta discussão, nos deparamos com o reconhecimento. Honneth (1992/2003) afirma o campo do amor — centrado na relação amorosa com a figura materna - como a primeira forma de reconhecimento, lançando sobre esta relação uma importância imprescindível para a constituição subjetiva. Nesse contexto, o autor segue as proposições de Hegel a partir das quais concebe o amor como "[...] uma relação de reconhecimento mútuo na qual a individualidade dos sujeitos encontra primeiramente confirmação" (Honneth, 1992/2003, p. 78). Em seguida, parte para a afirmação segundo a qual "[...] só na própria experiência de ser amado o sujeito querente é capaz de experienciar-se a si mesmo pela primeira vez como um sujeito carente e desejante" (p. 78). Ou seja, é a partir de uma relação de amor primordial, na qual o indivíduo pode ser reconhecido e afirmado em sua especificidade, que a linha da comunicação pode ser estabelecida como uma forma de contínua expressão e constituição de si mesmo. Em decorrência do estabelecimento da comunicação nesta via, o reconhecimento torna-se algo mútuo, implicando não apenas o ser reconhecido, mas o próprio reconhecer, sendo este último capaz de situar tanto o campo das identificações quanto das diferenças e assim criar a ideia de identidade. Não podemos deixar de atentar aqui para as considerações de Coli (2003), a partir das quais nos deparamos com a mudança da perspectiva artística sobre o trabalho de restauração ou apreciação do fragmento. Ao dotar este último de beleza em si fica clara a mudança de paradigmas a partir da qual se torna possível contemplar a ação do tempo, reconhecendo as marcas deixadas e as experiências passadas em 
vez de uma prevalência do intocado. Ou seja, percebemos a possibilidade de reconhecer artisticamente o objeto em si, carregado de história e moldado pelo tempo. Concomitante a isso, deparamo-nos com uma perspectiva que apresenta o olhar do outro como constitutivo na medida em que, ao privilegiar uma angulação específica sobre o sujeito - o fragmento em vez do todo ou vice-versa - constitui uma poética identitária distinta. Nesse contexto, Honneth (1992/2003) ainda declara que o amor também está ligado à forma de existência corporal, fazendo-nos atentar para o estabelecimento de uma relação que se dá não apenas no campo inter e intrapsíquico, mas também referido ao somático e que se expressa como uma forma de comunicação. Nesse ponto, o autor relaciona suas considerações ao campo das relações objetais em psicanálise no qual adentraremos agora a partir das considerações de Winnicott.

Apesar desse autor da escola inglesa e membro do Middle group não negar as formulações freudianas sobre o terreno das neuroses, afirma não ter muito a acrescentar a seu estudo. Como pediatra e em seu contato com crianças em meio à guerra, Winnicott pôde observar tanto a relação saudável entre bebês e suas mães quanto às marcas e consequências da perda do cuidado. Winnicott se destacou pela elaboração de uma teoria das relações de objeto em psicanálise tendo em vista o processo de desenvolvimento emocional primitivo partindo da ideia de saúde psíquica. A partir da proposta winnicottiana, vemo-nos diante de um outro que adquire uma função tão visceral que, no primeiro momento, apresenta-se como o próprio ambiente para o vir a ser.

A ideia de um bebê surge na obra de Winnicott como dotado de uma potencialidade à existência que lhe é própria. Nesse contexto, a figura materna estaria paradoxalmente indistinta ao infante e também capaz de lhe garantir a comunicação e reconhecibilidade que este necessita. Tendo em vista o desenvolvimento emocional posto em paralelo com a questão do reconhecimento, somos direcionados às considerações de Benjamin (1988/2018) que o apresenta como uma forma de interação ou seja, uma identificação do outro como semelhante, capaz de afetar e de ser afetado. Além disso, a autora ainda propõe o reconhecimento como a essência da responsividade nas interações. Vale destacar que o estudo da problemática do reconhecimento subjetivo não era trabalhado originalmente pela psicanálise que se dedicava ao estudo metapsicológico de uma dinâmica intrapsíquica. Tendo em vista as considerações de Benjamin, deparamo-nos com um psiquismo que almeja reconhecimento a fim de fundar-se. 


\section{ARTIGOS}

Seguindo estas ponderações deparamo-nos com as considerações de Winnicott. $\mathrm{O}$ autor da escola inglesa de psicanálise propõe a imagem de um bebê dotado de uma potencialidade que lhe é única, e que se expressa no meio — desde a vida intrauterina - a partir de movimentos corporais próprios, nomeados pelo autor de agressividade primária (Winnicott, 1955[1950]/2000b). Essa expressão motriz do bebê buscaria não apenas contorno e sustentação, mas um movimento de reconhecimento daquele bebê que começa seu longo processo em direção à individuação (Brum, 2019a). "Em minha opinião, o impulso agressivo inerente é extremamente poderoso e faz parte da pulsão que clama por relacionamentos. É, portanto, uma parte essencial do impulso primitivo de amor" (Winnicott, 1990/2017, p. 50). É justamente a partir dessa forma de comunicação que ainda desconhece a distinção entre eu-mãe-ambiente que o bebê começa o longo processo em direção a uma delimitação corporal distinta do meio, a sensação de habitar um corpo e a ideia de pertencimento a uma realidade compartilhada. Tudo isso só se torna possível a partir e graças à presença de um outro suficientemente bem adaptado ao infante. Nessa ideia de adaptação do ambiente ao bebê vemo-no diante não apenas da importância do reconhecimento na formação do indivíduo - algo que já destacamos neste trabalho - mas também nos deparamos com a concepção segundo a qual o reconhecimento se expressa para além da fala (enquanto nomeação) e do olhar (enquanto olhar direcionado ao indivíduo), referindo-se também no próprio sentir. ${ }^{1}$ A ideia aqui é o destaque de uma figura presente que, em sua adaptação às necessidades do bebê o cuida. A partir desse cuidado, o infante constitui-se como um ser distinto do ambiente, dando vazão ao desenvolvimento de sua própria singularidade, assim como a possibilidade de expressão desta no mundo. Afinal, traça-se a sensação de que coisas boas podem vir do contato com o mundo e de que a vida vale a pena ser vivida. "O indivíduo apenas se comunica com um mundo autoinventado, e as pessoas no ambiente apenas se comunicam com o indivíduo na medida em que podem criá-lo" (Winnicott, 1990/2017, p. 53). Neste contexto vale destacar que o cuidado com o bebê ganha aqui o caráter de um desenvolvimento da própria noção de si mesmo, assim como satisfação das necessidades egoicas (Lejarraga, 2015).

\footnotetext{
${ }^{1}$ É claro que com isso não estamos retirando a importância da nomeação e do direcionamento do olhar neste processo.
} 
Ao atuar como ambiente à figura do bebê, seu cuidador lhe garante não apenas as projeções e investimentos narcísicos que constituirão fantasmaticamente seu mundo interno, mas também recebem e acolhem o que daquele bebê se expressa diante de seus olhos e empaticamente. Sabemos que faz parte da adaptação suficientemente boa identificar os diferentes tipos de choro do infante, por exemplo, quando ele está mais cansado, mais irritado, mais alegre e mais manhoso. Tudo isso se torna um dialeto particular, uma forma de comunicação que ao mesmo tempo em que investe narcisicamente o infante, também reconhece quem ele é ou como ele se inscreve em sua tão recente existência. É nesse movimento - ser reconhecido - gradativamente passar a reconhecer — constituir-se —, que a existência é afirmada e paradoxalmente se torna possível expressar-se e desenvolver-se. Desta forma, a presença de uma testemunha atenta se apresenta como algo fundamental no constante e infindável processo de tornar-se.

\section{Presença e testemunho}

Nossas considerações vão ao encontro das proposições de Butler (2005/2015), quando ela afirma o reconhecimento como uma forma não apenas de testemunho do próprio sujeito, mas como um meio através do qual somos modificados em nossas relações. É justamente esse movimento que por um lado afirma a vivência do indivíduo e, por outro, se inscreve em uma presença capaz de (re)significar o vivido que se enuncia a potência do trabalho do analista. Afinal, se levarmos em consideração que é a partir do encontro com o outro que eu me constituo e me modifico em constante e fluido processo, a assunção de um lugar de testemunha do vivido do paciente por parte do analista promove mudanças significativas. Assim, embora o caminho de nosso trabalho não seja mais uma vez negar o ocorrido ou amputá-lo da vivência do indivíduo - o que por si só atualizaria o trauma sofrido - , as modificações que nossa prática são capazes de promover se inscrevem justamente em decorrência da capacidade de o sujeito se conciliar com sua história; (re)significando e aceitando o trauma como parte de seu passado e tornando possível não prender-se a ele como a âncora preditora de uma vida atemporal. Esta clínica nos coloca diante de uma potência de vida gigantesca frente ao desastre. Afinal, vemo-nos diante de sobreviventes que, mesmo fragmentados, resistem e insistem, apontando-nos um senso de esperança inerente ao próprio viver. De acordo com as palavras de Butler 


\section{ARTIGOS}

(2005/2015) " [...] o reconhecimento se torna o processo pelo qual eu me torno outro diferente do que fui e assim deixo de ser capaz de retornar ao que era" (p. 41), somos levados a atentar para a importância do nosso trabalho nesses casos, assumindo o lugar de testemunha como ferramenta capaz de atuar no processo de reconhecimento de nossos pacientes.

Tendo isso em vista, Butler ainda destaca um posicionamento direcionado ao outro como necessidade da humanidade, o que confere uma importância primordial ao reconhecimento como movimento constitutivo do sujeito. Ou seja, o lugar que o outro adquire na própria constituição subjetiva é tão primordial que se mantém como fundamental à manutenção do si mesmo, uma vez que esse processo de interpelação e constituição é algo contínuo e não apenas formador inicial da subjetividade. Estas formulações seguem a linha da concepção proposta por Winnicott de experiência:

[...] além do mundo pessoal interno da realidade psíquica, existe uma terceira coisa, igualmente importante, que é a experiência. A experiência é um trafegar constante na ilusão, uma repetida procura da interação entre a criatividade $e$ aquilo que o mundo tem a oferecer. A experiência é uma conquista da maturidade do ego, à qual o ambiente fornece um ingrediente essencial. Não é de modo algum alcançada sempre. (Winnicott, 1990/2017, p. 53; grifos nossos)

$\mathrm{Na}$ citação acima podemos perceber a fluidez que move todos os processos proposto por Winnicott, inclusive a própria relação. A ideia de experiência nos coloca diante da possibilidade - adquirida em decorrência do desenvolvimento emocional, temática que não exploraremos aqui — de troca com o meio a partir da segurança de que este será receptivo às expressões do indivíduo e a estas responderá de maneira singular. Levando isso em conta, colocamo-nos diante da ideia de reconhecimento, que, a nosso ver, está presente na própria concepção de ambiente suficientemente bom, amplamente discutida pelo autor (Winnicott, 1956/2000c). Afinal, esse nada mais é do que um meio disponível, atento e capaz de se adaptar às necessidades do indivíduo, inclusive falhando quando for necessário. Vele destacar que as falhas ambientais e suas consequências também são trabalhadas por Winnicott (1960/2007). Para esse autor essas desencadeariam formações defensivas e fragilidades no desenvolvimento egoico capazes de remeter o sujeito à angústia da desintegração, que pode se expressar das mais diversas formas - seja pela impossibilidade de integrar em uma única figura o objeto bom e mal, seja na angústia da não existência, ou, ainda, na formação de uma carapaça falsa que engloba o verdadeiro self a fim de protegê-lo, e assim por diante. É justamente ao dar lugar, olhar e voz, ou seja, um contorno atento capaz de assegurar sua 
existência no próprio holding que o indivíduo pode emergir. Afinal, essa faísca de luminosidade própria, essa centelha de esperança, clama por afirmação, por um olhar capaz de testemunhar sua veracidade e espontaneidade.

Nessa linha, devemos atentar que a expressão de si e narrativa da própria história possuem por si só um importante papel no que tange ao processo de elaboração e significação. Complementarmente, é uma característica do discurso seu direcionamento a um interlocutor. $\mathrm{O}$ dispositivo analítico se apresenta como uma ferramenta testemunhal fundamental no caso de pacientes que sofreram os efeitos avassaladores do traumático, uma vez que paradoxalmente parte-se do princípio de que a narrativa não faz parte do narrável (Gondar \& Antonello, 2016). Desta forma, podemos nos deparar com uma função natural, a qual o setting analítico tenta recriar. Essa se refere à necessidade da expressão e narrativa de si para um outro presente e atento, capaz de atuar como ferramenta fundamental no processo de elaboração significação e ressignificação do indivíduo sobre si e de suas experiências. Nesse contexto, Gondar e Antonello (2016) afirmam, "O apelo ao terceiro a testemunha — é um apelo a algo ou alguém que estava ausente no momento em que a situação traumática se deu. É um apelo ao cuidado, à salvação, é, consequentemente, a superação do trauma" (p. 18). E novamente vemo-nos diante do contraste entre desmentido e reconhecimento, ausência de uma figura atenta de cuidado diante do ocorrido traumático e presença do analista na clínica na atualidade do tratamento. Ou seja, tanto na teoria ferencziana do trauma quanto do desenvolvimento emocional primitivo proposto por Winnicott, se expressa a necessidade da presença de uma figura capaz de sustentar e afirmar as vivências do indivíduo, suas experiências e expressões espontâneas. Para o primeiro autor tal importância se expressa através de uma falha, enquanto para o segundo como um movimento natural.

Considerar o reconhecimento o avesso do desmentido implica dizer que efeitos traumáticos podem ocorrer quando alguém não é reconhecido na sua condição de sujeito. De fato, não é possível uma posição neutra a este respeito: ou se reconhece alguém ou se o desmente, sendo a neutralidade uma atitude produtora de desmentidos — atitude para a qual Ferenczi já teria nos alertado, ao escrever o quanto a insensibilidade ou frieza dos analistas pode ser traumatogênica. Desse modo, o desmentido, enquanto não validação das percepções e dos afetos de um sujeito, pode ser entendido como um reconhecimento recusado. (Gondar, 2012, p. 200)

Desta forma, a clínica se apresenta como um ambiente no qual um novo começo torna-se possível na medida em que é a partir da construção de um 


\section{ARTIGOS}

meio confiável, construído na presença do analista como testemunha da história do sujeito, que se pode reviver o traumático como uma vivência real passível de elaboração e que pode abrir caminho para a possibilidade de uma nova vida (Ferenczi, 1934/2011d). Deste modo, tanto na clínica do trauma quanto no processo de desenvolvimento subjetivo nos vemos diante não de um movimento repetitivo, mas da possibilidade de criação de algo novo. Gondar e Antonello (2016) caracterizam o lugar de testemunha assumido pelo analista ao de uma função materna nos primórdios da vida, a partir da consideração de que o analista não deveria ocupar um lugar da lei ou da norma, mas de algo natural, não tão bem demarcado, não se encontrando nem dentro nem fora, atuando como um laboratório das expressões intensivas da afetividade; finalizando por aproximar o espaço analítico ao transicional. Acreditamos que a assunção de um lugar de testemunha por parte do analista na clínica do traumático se aproximaria ao da figura materna, pois implica reconhecer o indivíduo em todas as expressões que podem emergir na clínica.

Nesse sentido, reafirmamos a importância de uma presença atenta, capaz de reconhecer o indivíduo em suas expressões particulares, necessidades e desejos como parte fundamental não apenas do desenvolvimento psíquico nos estágios iniciais do desenvolvimento, mas ao longo de toda a vida. Afinal, como sabemos (Winnicott, 1945/2000a; Butler, 2005/2015; Honneth, 1992/2003) o processo de tornar-se é uma construção contínua e marcada pela resposta dada pelo outro diante da expressão de si. Logo, a capacidade de testemunhar as expressões particulares do sujeito acompanhando-o na construção de sua história e apresentação de suas experiências no campo analítico, se apresenta como um posicionamento ético em prol da singularidade da vida. Tal se afirma na medida em que, ao reconhecer o indivíduo adotando um lugar afirmativo perante a narrativa de si mesmo, constrói-se na presença do analista um lugar pertencente ao paciente a partir do qual este adquire a confiança capaz de assegurar a si mesmo. Nesse contexto, a certeza sobre si e sua própria experienciação da vida e do mundo é construída. Ou, no contexto analítico, a partir da criação de um meio adaptado e seguro, reconstruída.

\section{Considerações finais}

No presente artigo propomos traçar um contraponto entre a negação do próprio sujeito em decorrência do trauma desestruturante e sua afirmação a partir do reconhecimento possibilitado por um ambiente adaptado às suas 
necessidades. Nesse contexto deparamo-nos com a potência que o encontro com o outro é capaz de adquirir, uma vez que este promove modificações sobre o indivíduo que não são passíveis de retorno (Butler, 2005/2015).

Logo, o trauma nos abre caminho para pensarmos sua faceta oposta, o reconhecimento. Este último se inscreve não apenas como algo natural ao desenvolvimento e constituição subjetiva, mas como posicionamento ético e político na própria clínica psicanalítica. Tais considerações, além de nos colocarem diante do quão patológico pode se tornar em alguns casos o distanciamento e frieza do analista, também nos mostra os efeitos nocivos que a impossibilidade de adotar uma postura de reconhecimento atuando como testemunha da vida e vivências do paciente podem desencadear. Afinal, o sujeito que busca a análise almeja o reconhecimento de sua dor e sofrimento, da expressão de seu sintoma enquanto algo do qual se queixa, mas que também é uma parte de si, da sua história, dos caminhos escolhidos e de sua sobrevivência diante das inevitáveis batalhas. Atentarmos para a questão do reconhecimento como movimento fundamental à constituição psíquica do indivíduo e definição de um lugar a partir do qual ele se torna capaz de falar sobre si, nos coloca diante da criatividade potencial da qual somos dotados. Com isso queremos dizer que o reconhecimento se expressa como uma forma de afirmação e percepção de nós mesmos pelo outro, em um encontro que encoraja nosso eterno movimento de construção e reconstrução, mantendo a assertividade que, ao ser alcançada, possibilita contorno e definição próprios, assim como a criação da segurança sobre nós mesmos e nossas experiências. Dito de outro modo, o reconhecimento possibilita o desenvolvimento do sentimento de certeza de si, a partir do qual o indivíduo se sente confiante e seguro para se relacionar verdadeiramente com o mundo. Afinal, seguindo as palavras de Honneth (1992/2003) “[...] faz parte da 'efetividade' de um ser-para-si 'ser reconhecido pelo outro, ser considerado por ele como absoluto"” (p. 91).

\section{Referências}

Benjamin, J. (2018). Beyound Doer and Done to: Recognition theory, intersubjetivity and the third. New York, NY: Routledge. (Trabalho original publicado em 1988).

Brum, S. (2018, jul/dez.). A positividade de uma vida em fragmentos. Cadernos de Psicanálise, 40(39), 125-144.

Brum, S. (2019, set.). Motor criativo: apresentação da noção de desejo a partir do texto winnicottiano. Rabisco, 9(1), 121-134. 
Brum, S. (2019, jul/dez.). A crise dos sentidos: uma perspectiva ferencziana. Tempo Psicanalítico, 51(2), 224-243. (no prelo),

Brum, S., Câmara, L., \& Sanzana, D. (2020). Do desprazer da realidade ao encontro com o trauma: trabalhando o problema da afirmação do desprazer. Cadernos de Psicanálise, 42(42), 135-151.

Butler, J. (22015) Relatar a si mesmo: crítica da violência ética. Rio de Janeiro: Grupo Autêntica. (Trabalho original publicado em 2005).

Coli, J. (2003). O sonho de Frankenstein. In A. Novaes (Org.), O homem-máquina: a ciência manipula o corpo. São Paul, SP: Companhia das Letras.

Ferenczi, S. (2011a). Transferência e introjeção. In Obras completas Psicanálise I. São Pau, SP: Martins Fontes. (Trabalho original publicado em 1909).

Ferenczi, S. (2011b). Thalassa: ensaio sobre a teoria da genitalidade. In Obras completas Psicanálise III. São Paulo, SP: Martins Fontes. (Trabalho original publicado em 1924).

Ferenczi, S. (2011c). A criança mal acolhida e sua pulsão de morte. In Obras completas Psicanálise IV. São Paulo, SP: Martins Fontes. (Trabalho original publicado em 1929).

Ferenczi, S. (2011d). Reflexão sobre o trauma. In Obras completas Psicanálise IV. São Paulo, SP: Martins Fontes. (Trabalho original publicado em 1934).

Freud, S. (2016). Três ensaios sobre a teoria da sexualidade. In Obras Completas (vol .VI). São Paulo, SP: Companhia das letras. (Trabalho original publicado em 1905).

Gondar, J. (2012, jul/dez.). Ferenczi como pensador político. Cadernos de Psicanálise, 34(27), 193-210.

Gondar, J., \& Antonello, D. (2016). O analista como testemunha. Psicologia USP, 27(1), 16-23.

Green, A. (1988). Narcisismo de vida, narcisismo de morte. São Paulo, SP: Escuta.

Honneth, A. (2003). Luta por reconhecimento: a gramática moral dos conflitos sociais. São Paulo, SP: Editora 34. (Trabalho original publicado em 1992).

Honneth, A. (2018). Reificação. São Paulo, SP: Editora Unesp. (Trabalho original publicado em 2006).

Kupermann, D. (2019). Porque Ferenczi? São Paulo, SP: Zagodoni.

Lejarraga, A. L. (2008, dez.). Clínica do trauma em Ferenczi e Winnicott. Natureza humana, 10(2). Recuperado em 27 dez. 2015 de < http://pepsic.bvsalud.org/scielo. php?script=sci_arttext\&pid=S1517-24302008000200005 $>$.

Lejarraga, A. L. Sexualidade infantil e intimidade: diálogos winnicottianos. Rio de Janeiro, RJ: Gramond, 2015.

Pinheiro, T. (1995). Ferenczi do grito a palavra. Rio de Janeiro, RJ: Jorge Zahar.

Winnicott, D. W. (2000a). Desenvolvimento emocional primitivo. In Da pediatria à 
psicanálise (pp. 218-232). Rio de Janeiro, RJ: Imago. (Trabalho original publicado em 1945).

Winnicott, D. W. (2000b). A agressividade em relação ao desenvolvimento emocional. In Da pediatria à psicanálise (pp. 288-304). Rio de Janeiro, RJ: Imago. (Trabalho original publicado em 1955[1950]).

Winnicott, D. W. (2000c).A preocupação materna primária. In Da pediatria à psicanálise (pp. 399-40. Rio de Janeiro, RJ: Imago. (Trabalho original publicado em 1956).

Winnicott, D. W. (1960/2007). Distorções do ego em termos de falso e verdadeiro self. In $O$ ambiente e os processos de maturação (pp. 128-139). São Paulo, SP: Artmed. (Trabalho original publicado em 1960).

Winnicott, D. W. (02017). O gesto espontâneo. São Paulo, SP: Martins Fontes. (Trabalho original publicado em 1990).

\section{Resumos}

(Trauma and recognition in psychoanalytic clinic)

This article aims to outline considerations about recognition in the psychoanalytic clinic by contrasting it with trauma. In this context, recognition presents itself not only as a form of care promoted by sufficient environmental adaptation, but also as an ethical position assumed in the clinic itself. On the other hand, trauma emerges when the environment fails to recognize the individual's needs and to mediate his vulnerability in his relationship with the environment.

Key words: Trauma, recognition, testimony, vulnerability, presence

(Trauma et reconnaissance à la clinique psychanalytique)

Cet article vise à discuter la reconnaissance en clinique psychanalytique en contrepoint au traumatisme. Dans ce contexte, nous sommes confrontés à la reconnaissance qui, à son tour, se présente non seulement comme la forme de soins promue par une adaptation environnementale suffisamment bonne, mais aussi comme une position éthique assumée dans la clinique elle-même. D'autre part, le traumatique émerge comme un échec de l'environnement à reconnaître les besoins de l'individu et à médiatiser sa vulnérabilité dans sa relation à l'environnement..

Mots clés: Trauma, reconnaissance, témoignage, vulnérabilité, présence

(Trauma y reconocimiento en la clínica psicoanalítica)

Trazando un contrapunto entre el reconocimiento y el trauma, este artículo tiene como objetivo elaborar consideraciones sobre el reconocimiento en la clínica 
psicoanalítica. En este contexto, nos deparamos con el reconocimiento que, a su vez, no sólo se presenta como una forma de atención promovida por una adaptación ambiental suficientemente buena, sino también como una postura ética asumida en la propia clínica. Por otro lado, lo traumático surge cuando el ambiente falla al reconocer las necesidades del individuo y al mediar su vulnerabilidad en su relación con el medio.

Palabras clave: Trauma, reconocimiento, testimonio, vulnerabilidad, presencia

Citação/Citation: Brum, S. (2021, março). Trauma e reconhecimento na clínica psicanalítica. Revista Latinoamericana de Psicopatologia Fundamental, 24(1), 75-91. http://dx.doi. org/10.1590/1415-4714.2021v24n1p75.5.

Editoras/Editors: Profa. Dra. Ana Maria R. G. Oda

Submetido/Submitted: 7.12.2020 / 12.7.2020 Revisado/Revised: 15.9.2020 / 9.15.2020

Aceito/Acepted: 24.9 .2020 / 9.24.2020

Copyright: (C) 2009 Associação Universitária de Pesquisa em Psicopatologia Fundamental/ University Association for Research in Fundamental Psychopathology. Este é um artigo de livre acesso, que permite uso irrestrito, distribuição e reprodução em qualquer meio, desde que o autor e a fonte sejam citados / This is an open-access article, which permits unrestricted use, distribution, and reproduction in any medium, provided the original authors and sources are credited.

Financiamento/Funding: Este trabalho não recebeu apoio / This work received no funding.

Conflito de interesses/Conflict of interest: A autora declara que não há conflito de interesses. / The author declares that there is no conflict of interest.

\section{STEPHANIE BRUM}

Psicóloga, formada pela Universidade Federal do Rio de Janeiro - UFRJ (Rio de Janeiro, RJ, Br); Mestre em Teoria Psicanalítica pela mesma Universidade; Doutoranda em Psicologia Clínica pela Pontifícia Universidade Católica do Rio de Janeiro - PUC-Rio (Rio de Janeiro, RJ, Br); Membro do Grupo de Estudos e Pesquisa Nebulosa Marginal (Rio de Janeiro, RJ, Br). Atende em consultório particular no Rio de Janeiro, RJ. Br.

Rua André Rocha, 750/427 - Taquara

22730-522 Rio de Janeiro, RJ, Br

stephanie-brum@hotmail.com

https://orcid.org/0000-0001-6398-2791

This is an open-access article, which permits unrestricted use, distribution, (cc) BY-NC and reproduction in any medium for non-commercial purposes provided the original authors and sources are credited.

Rev. Latinoam. Psicopat. Fund., São Paulo, 24(1), 75-91, mar. 2021 